\title{
A MICRO-CT STUDY OF CHANGES IN THE INTERNAL STRUCTURE OF DAQING AND YAN'AN OIL SHALES AT HIGH TEMPERATURES
}

\author{
JING ZHAO, DONG YANG ${ }^{*}$, ZHIQIN KANG, \\ ZENGCHAO FENG
}

Institute of Mining Technology, Taiyuan University of Technology

Taiyuan 030024, P. R. China

\begin{abstract}
A high-precision computed tomography (CT) experimental analysis system was used to perform a non-invasive CT scanning of oil shales (OS) from Daqing and Yan'an counties, Heilongjiang and Shanxi provinces, respectively, both northeastern China, in order to study changes in their internal structure at high temperatures. The formation and pattern of pores and fractures with increasing temperature was examined. Professional CT analysis software was used to statistically calculate porosities. The experimental results indicated that the thermal decomposition of organic matter at high temperatures was a major factor causing changes in the internal structure of Daqing oil shale. When the temperature exceeded $200{ }^{\circ} \mathrm{C}$, large heterogeneous pores were formed in the originally solid material due to the expulsion of the gas and oil generated by thermal pyrolysis of organic matter at high temperature. With a further increase in temperature, the pores expanded and became interconnected by fractures. The heterogeneous thermal expansion was a major factor causing changes in the internal structure of Yan'an oil shale. After the temperature reached $200{ }^{\circ} \mathrm{C}$, numerous fractures parallel to the primary strata were formed, which propagated and expanded with increasing temperatures. In summary, high temperatures changed the compact structure of oil shale into a porous medium with well-developed pores and fractures. As the temperature rose from 20 to $600{ }^{\circ} \mathrm{C}$, the porosity of Daqing oil shale increased from 2.23 to $31.61 \%$ (a factor of 14.2), that of Yan'an oil shale increased from 2.70 to $8.86 \%$ (a factor of 3.3).
\end{abstract}

Keywords: oil shale, computed tomography (CT), pore, high temperature.

\section{Introduction}

With increasing demand for energy, oil shale has become an important alternative energy source to petroleum and natural gas [1-2]. China has abundant oil shale resources. According to the latest assessment of national

\footnotetext{
${ }^{*}$ Corresponding author: email ydscience@hotmail.com
} 
oil shale resources conducted by Jilin University, China, these total 720 billion tons of oil shale, or 48 billion tons of shale oil, ranking second in the world [3-8]. The exploitation and utilization of oil shale have been the focus of numerous scientific studies, and can bring considerable economic benefits. The aboveground and underground retorting techniques are two possible methods for oil shale exploitation. The latter technique is more suitable for processing oil shales that hold large reserves and are deeply buried $(>300 \mathrm{~m})$. Also, it is more economical and environmentally friendly.

The underground retorting technique consists in the following. The in situ heating of underground oil shale pyrolyzes the shale into gas and oil, which flow in the fractures and pores of the strata. Oil and gas are transported to the surface via production wells, and then separated (Fig. 1) [9-12]. Under natural conditions, oil shale has low porosity, and the existence of a small number of natural pores and fractures cannot ensure the formation and smooth flow of gas and oil in the strata. Therefore, oil shale should be heated to high temperatures to produce channels for the smooth movement of gas and oil. Kang et al. conducted CT examination and analysis of the thermal cracking process of oil shale from Fushun of Liaoning province, China, at high temperature [12].

The results showed that the threshold temperature at which the thermal cracking of the shale takes place is $350{ }^{\circ} \mathrm{C}$. Therefore, investigation of the

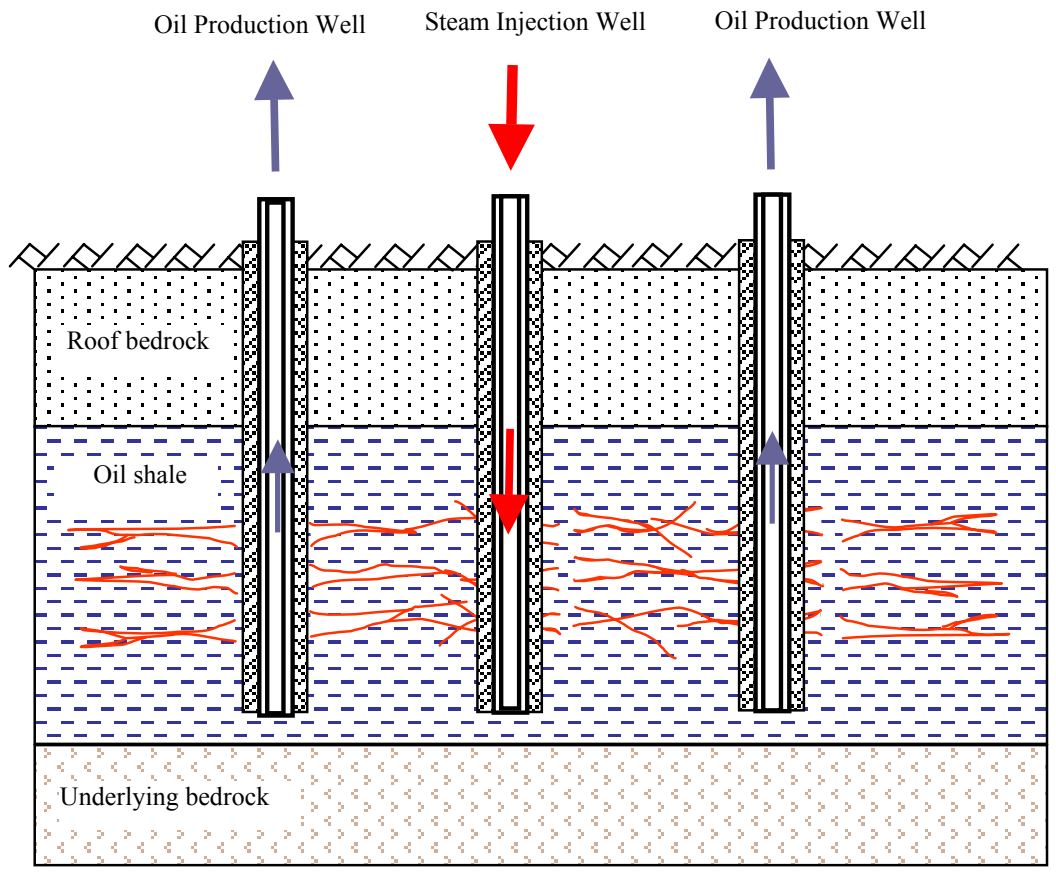

Fig. 1. Oil shale in situ steam drive process detail. 
change of the internal structure of oil shale with increasing temperatures is important for improving the efficiency of gas and oil recovery after the pyrolysis of oil shale.

\section{Micro-CT experiment on oil shale at high temperatures}

\subsection{Experimental facilities}

This experiment used a custom-built $\mu \mathrm{CT} 225 \mathrm{kVFCB}$ high-precision $(\mu \mathrm{m})$ micro-CT experimental analysis system. The system was developed for a micro-CT scanning of Daqing and Yan'an oil shales, to study changes in their internal structure at various temperatures. Micro-CT images showing the internal structure of oil shales at temperatures ranging from 20 to $600{ }^{\circ} \mathrm{C}$ were obtained. Professional CT analysis software was used for statistical analysis of oil shale porosity. The $\mu \mathrm{CT} 225 \mathrm{kVFCB}$ system includes a microfocus X-ray device, a digital plane detector, a high-precision revolving stage, a test specimen, a motor support, a mechanism for moving the specimen horizontally, and a data collection and analysis system (Fig. 2).

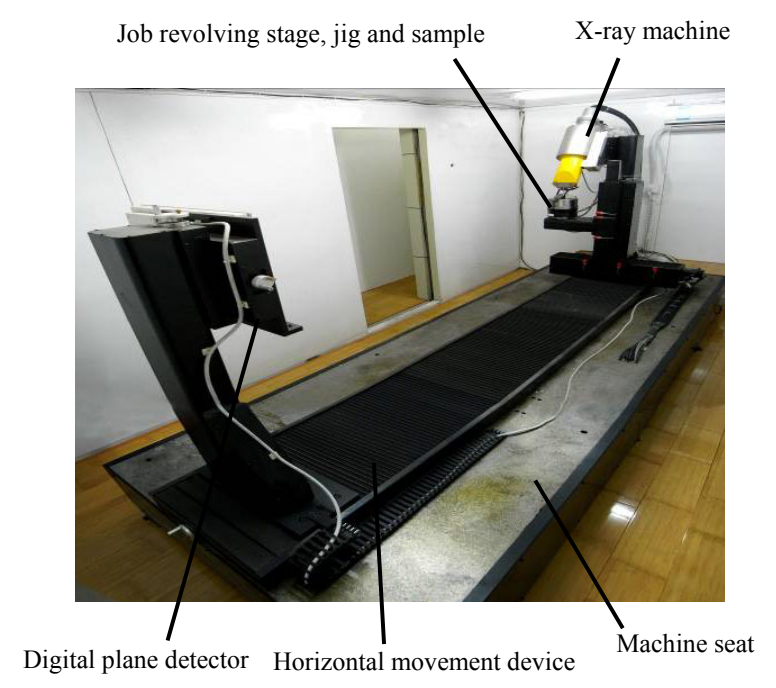

Fig. 2. Micro-CT experimental system.

\section{Methods}

Figure 3 shows a photograph of the sampling points of Daqing and Yan'an oil shales. Originating from the north of the Songliao Basin, Heilongjiang province, northeastern China, and having taken shape during the Early Tertiary Eocene, the Daqing oil shale is a fluvio-lacustrine deposit, which is 
blocky, with a compact texture and grayish-brown color. Originating from the north of the Tongchuan-Ordos Basin of Shaanxi province, northeastern China, and having taken shape during the Late Middle Triassic, the Yan'an oil shale is a large inland lacustrine deposit, which has an obvious shaly structure, with a loose texture and blackish-brown color. The oil yield of Daqing and Yan'an oil shales is 15.02 and $7.85 \%$, respectively. In this experiment, a small cylindrical specimen with a diameter of $5.0 \mathrm{~mm}$ and a height of $10 \mathrm{~mm}$ was cored from a large block of oil shale. The test specimen was then placed on the rotary table of the micro-CT scanner. The sample was first CT-scanned at room temperature and then transferred to a high-temperature electric furnace, into which nitrogen was injected to prevent oxidation of oil shale, thus increasing experimental precision. After the temperature reached $100{ }^{\circ} \mathrm{C}$, the test specimen was kept at this temperature for $30 \mathrm{~min}$ before being naturally cooled to room temperature in the electric furnace. The sample was then re-scanned. Five similar experiments were then conducted at successive furnace temperatures of 200,300, 400, 500 and $600{ }^{\circ} \mathrm{C}$.

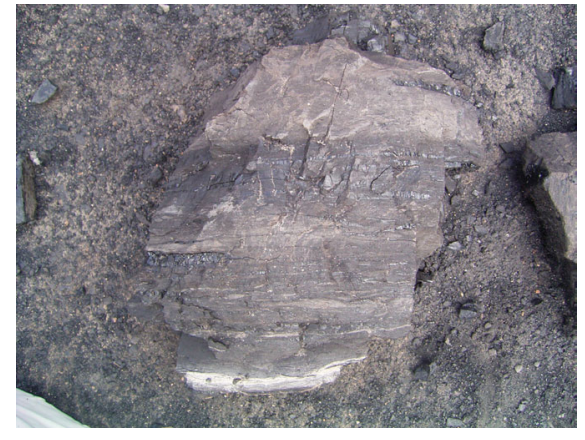

(a) Daqing

Scale $100 \mathrm{~mm}$

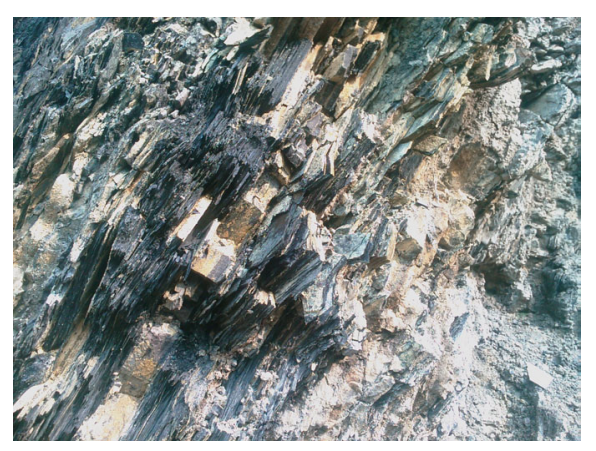

(b)Yan'an Scale $100 \mathrm{~cm}$

Fig. 3. Oil shale sampling points.

\section{Results and discussion}

\subsection{Changes in oil shale structure with increasing temperature}

\subsubsection{Daqing oil shale}

Micro-CT images revealing changes in the internal structure of Daqing oil shale at different temperatures are depicted in Fig. 4. The images suggest that the changes occurred in three stages: at temperatures from 20 to $200{ }^{\circ} \mathrm{C}$, from 200 to $500{ }^{\circ} \mathrm{C}$ and from 500 to $600{ }^{\circ} \mathrm{C}$. 


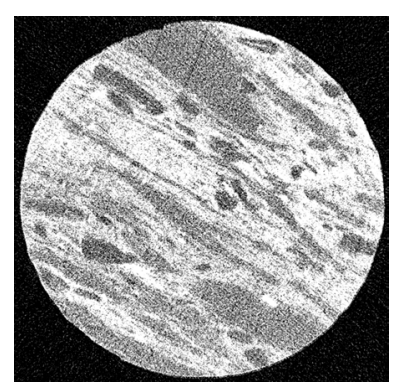

$\mathrm{T}=20^{\circ} \mathrm{C}$

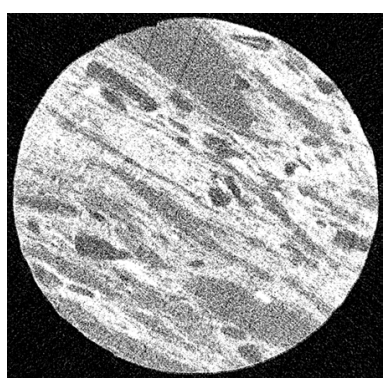

$\mathrm{T}=100^{\circ} \mathrm{C}$

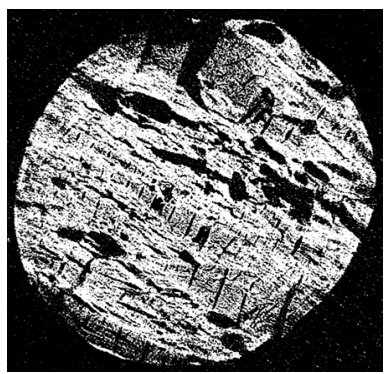

$\mathrm{T}=400{ }^{\circ} \mathrm{C}$

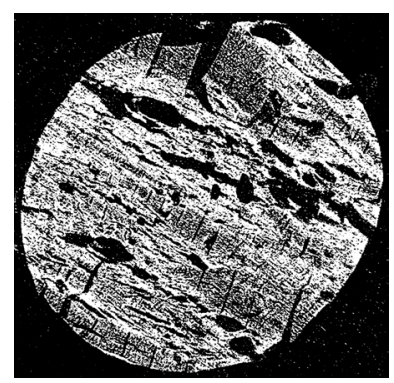

$\mathrm{T}=200^{\circ} \mathrm{C}$

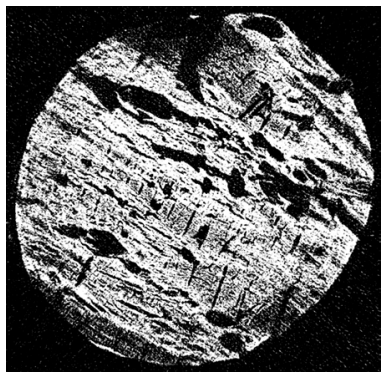

$\mathrm{T}=500^{\circ} \mathrm{C}$

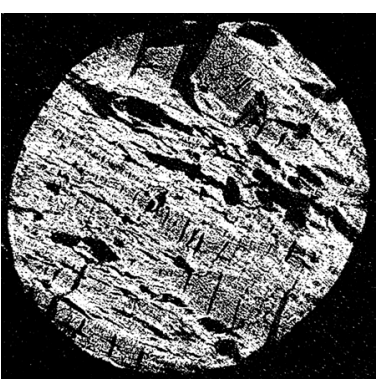

$\mathrm{T}=300^{\circ} \mathrm{C}$

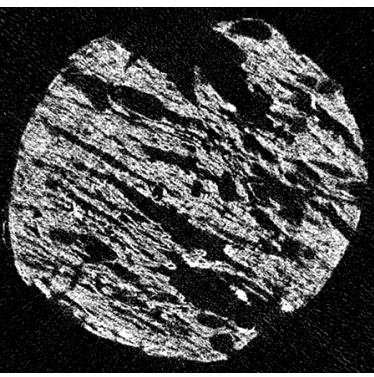

$\mathrm{T}=600^{\circ} \mathrm{C}$

Fig. 4. CT images showing changes of pores and fissures in Daqing oil shale at different temperatures.

\subsubsection{1. $20-200^{\circ} \mathrm{C}$}

At room temperature, the internal structure of Daqing oil shale was mostly heterogeneous, with minerals in various forms. According to its chemical composition, there were two parts in micro-CT images: one part is black, kerogen-rich and less dense, the other is lighter, kerogen-poor and mineralrich. After heating to $100{ }^{\circ} \mathrm{C}$, no obvious changes in the internal structure of the shale were observed. At $200^{\circ} \mathrm{C}$, its internal structure underwent significant changes, with the formation of numerous flat pores. Many microfractures perpendicular to the pore orientation appeared. These changes occurred as follows. When the temperature increased to $200{ }^{\circ} \mathrm{C}$, the organic matter with low chemical bond energy was thermally decomposed into gas and oil, thereby forming flat pores. The generation of micro-fractures was mainly due to the differences in thermal expansion between mineral 
particles. As seen in the images, the micro-fractures were the major links connecting the pores, providing smooth channels for the output of gas and oil after the pyrolysis.

\subsubsection{2. $200-500{ }^{\circ} \mathrm{C}$}

As the temperature increased, more organic matter was thermally decomposed, resulting in the further expansion and even interconnection of the existing pores. Meanwhile, the quantity, length and width of micro-fractures steadily increased. Structural changes were generally progressive, with no obvious abrupt changes.

\subsubsection{3. $500-600{ }^{\circ} \mathrm{C}$}

At $600{ }^{\circ} \mathrm{C}$, the structure of Daqing oil shale underwent major changes. Large amounts of the organic matter, which had not decomposed at lower temperatures, began to decompose at $500-600{ }^{\circ} \mathrm{C}$. A substantial increase in both the quantity and size of pores was detected. Fig. 4 shows that the solid framework of Daqing oil shale was completely decomposed into inorganic matter, indicating a complete thermal decomposition at $600{ }^{\circ} \mathrm{C}$.

\subsubsection{Yan'an oil shale}

Micro-CT images revealing changes in the internal structure of Yan'an oil shale at different temperatures (the specimen surface is perpendicular to the bedding) are shown in Fig. 5. The images suggest that changes occurred during two stages: at $20-200{ }^{\circ} \mathrm{C}$ and $200-600{ }^{\circ} \mathrm{C}$.

\subsubsection{1. $20-200^{\circ} \mathrm{C}$}

At room temperature, there was a primary fracture extending along the bedding surface of Yan'an oil shale (highlighted in Fig. 5). When the temperature increased to $100{ }^{\circ} \mathrm{C}$, no changes in the internal structure of the shale occurred, implying that temperatures below $100{ }^{\circ} \mathrm{C}$ had no impact on it. At $200{ }^{\circ} \mathrm{C}$, fractures of variable sizes were formed, and concentrated at the interactive area of the bedding. All the fractures extended along the primary bedding surface. The observed pattern can be explained in terms of the contrasting thermal expansion properties of different mineral constituents. On heating, the varying thermal expansion resulted in thermal stresses between the mineral particles. When the thermal stresses exceeded the yield limit of the cementing agents between the particles, the fractures developed and propagated rapidly along the weak bedding surfaces, especially at the interactive area of the bedding where the quantity of fractures generated by thermal cracking was the highest. 


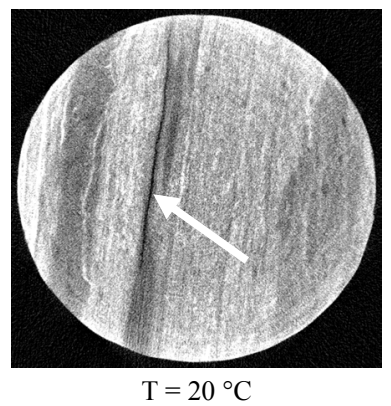

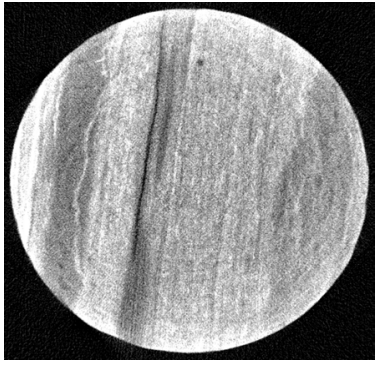

$\mathrm{T}=100^{\circ} \mathrm{C}$

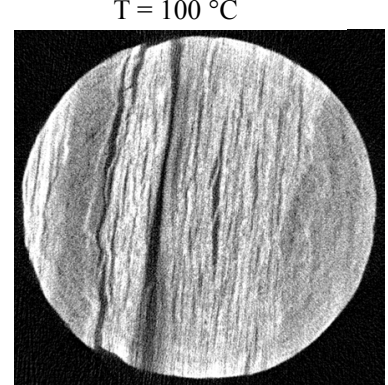

$\mathrm{T}=400^{\circ} \mathrm{C}$

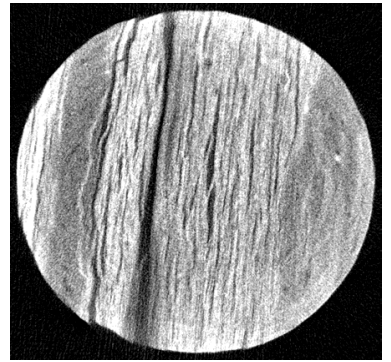

$\mathrm{T}=200^{\circ} \mathrm{C}$

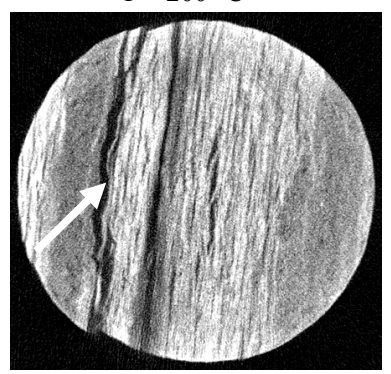

$\mathrm{T}=500^{\circ} \mathrm{C}$

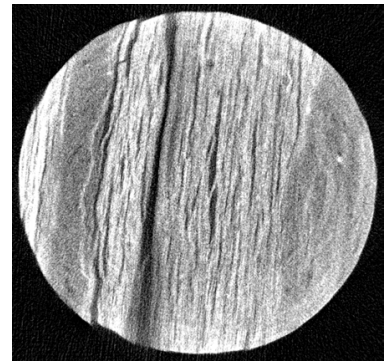

$\mathrm{T}=300^{\circ} \mathrm{C}$

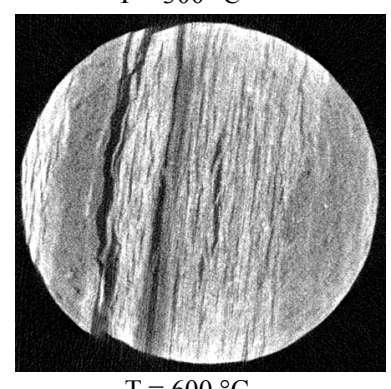

$\mathrm{T}=600^{\circ} \mathrm{C}$

Fig. 5. CT images showing changes of pores and fissures in Yan'an oil shale at different temperatures (the specimen surface is perpendicular to bedding).

\subsubsection{2. $200-600^{\circ} \mathrm{C}$}

As the temperature, increased from 200 to $600{ }^{\circ} \mathrm{C}$, the number of fractures in the Yan'an oil shale increased slightly, the length and width of the existing fractures increasing noticeably. A large fracture belt at the the interactive area of the bedding is highlighted in Fig. 5. This is due to the thermal decomposition of organic matter, which generated shale oil and gas. After being heated to higher temperatures, shale oil and gas can spew out at a high speed. The corresponding volume will expand synchronously.

\subsection{Variation in oil shale porosity with temperature}

The pores and fractures in oil shale are the main channels through which the gas and oil generated from the thermal decomposition of oil shale can be stored, or seep. The higher the porosity, the easier the recovery of gas and oil. The porosity of oil shale also varies with the depletion of reactants, 
which again directly affects the seepage of oil and gas. Thus, a better understanding of the change in oil shale porosity with temperature is of great significance for analyzing the seepage and production of gas and oil after the thermal decomposition of oil shale, as well as for guiding in situ exploitation of oil shale. Professional CT analysis software ( oil shale can be regarded as a medium consisting of the void space and solid skeleton) was used to calculate the volume of pores and fractures in Daqing and Yan'an oil shales at different temperatures (Table 1).

From Figures 6 and 7 it is seen that variations in the porosity of Daqing and Yan'an oil shales with increasing temperature showed similar trends. After heating oil shales from 20 to $100{ }^{\circ} \mathrm{C}$, their porosity did not vary significantly, because only a small amount of water vapor was generated and this negligibly influenced the internal structure of the shales. At temperatures from 100 to $200{ }^{\circ} \mathrm{C}$, the porosity of both oil shales rapidly increased, partly due to the onset of thermal decomposition of organic matter and partly because thermal cracking occurred due to the anisotropic thermal expansion

Table 1. Oil shale porosity at different temperatures

\begin{tabular}{|c|c|c|}
\hline Temperature, ${ }^{\circ} \mathrm{C}$ & Porosity of Daqing oil shale, $\%$ & Porosity of Yan'an oil shale, $\%$ \\
\hline 20 & 2.23 & 2.70 \\
100 & 2.31 & 2.76 \\
200 & 18.44 & 7.24 \\
300 & 19.96 & 7.28 \\
400 & 20.79 & 7.79 \\
500 & 23.01 & 8.07 \\
600 & 31.61 & 8.86 \\
\hline
\end{tabular}

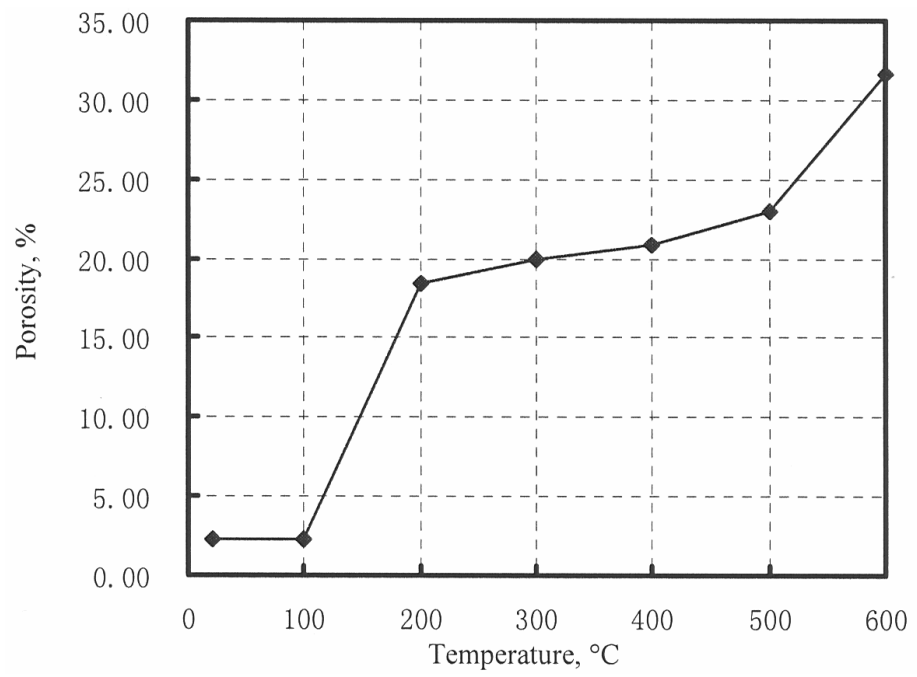

Fig. 6. Curve of variation of Daqing oil shale porosity with temperature. 


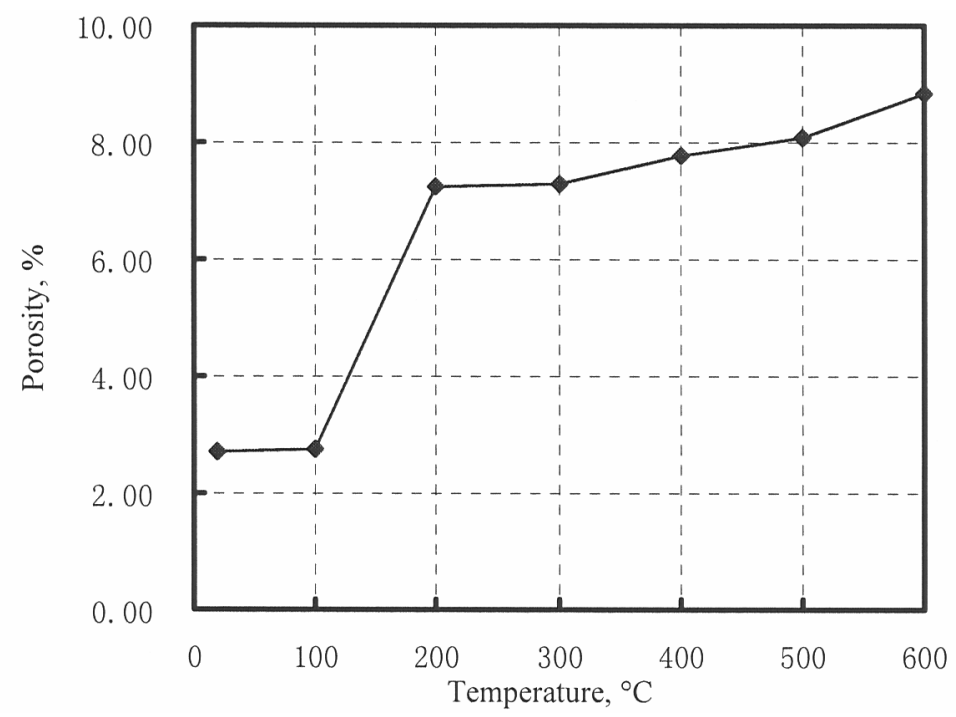

Fig. 7. Curve of variation of Yan'an oil shale porosity with temperature.

of various mineral particles. As the temperature increased from 200 to $600{ }^{\circ} \mathrm{C}$, large quantities of organic matter were thermally decomposed, resulting in the rapid development of large-scale pore and fracture networks, and increased porosity. At temperatures from 20 to $600{ }^{\circ} \mathrm{C}$, the porosity of Daqing oil shale increased from 2.23 to $31.61 \%$ (a factor of 14.2), that of Yan'an oil shale from 2.70 to $8.86 \%$ (a factor of 3.3). Under the action of these high temperatures oil shale, which initially allowed no seepage of gas and oil, was transformed into a porous medium with well-developed fractures and pores.

\section{Conclusions}

The $\mu \mathrm{CT} 225 \mathrm{kVFCB}$ high-precision $(\mu \mathrm{m}) \mathrm{CT}$ experimental analysis system was used to study changes in the internal structure of Daqing and Ya'an oil shales with increasing temperature. Based on the experimental results, the following conclusions can be drawn:

1. At temperatures below $100{ }^{\circ} \mathrm{C}$, no changes in the internal structure of Daqing and Yan'an oil shales were observed. When the temperature increased to $200^{\circ} \mathrm{C}$, the oil shales' internal structure underwent significant changes, due to the formation of numerous pores and fractures. At this temperature, the major factors causing changes in the internal structure were the thermal decomposition of organic matter in the Daqing oil shale, and the thermal cracking due to the thermal expansion of different mineral constituents in the Yan'an oil shale. At temperatures from 200 to $600^{\circ} \mathrm{C}$, the more intensive 
thermal decomposition of organic matter resulted in a significant increase in the size of pores and fractures in both Daqing and Yan'an oil shales.

2. As the temperature increased from 20 to $600{ }^{\circ} \mathrm{C}$, the porosity of Daqing oil shale increased from 2.23 to $31.61 \%$ (a factor of 14.2), that of Yan'an oil shale from 2.70 to $8.86 \%$ (a factor of 3.3). Under the action of these high temperatures oil shale, which initially allowed no seepage of gas and oil, was transformed into a porous medium with well-developed pores and fractures.

\section{Acknowledgments}

The authors are grateful for the financial support within the Ph.D. programs from the Special Scientific Research Foundation of the Ministry of Education of China (No. 20101402120011), and the Nature Science Foundation of Shanxi Province, China (No. 2010011014-2).

\section{REFERENCES}

1. Heller, A. Chemical engineering challenges and investment opportunities in sustainable energy. ChemSusChem., 2008, 1(7), 651-652.

2. Dyni, J. R. Oil shale developments in the United States. Oil Shale, 2006, 23(2), 97-98.

3. Liu, Z. J., Dong, Q. S., Ye, S. Q. et al. The situation of oil shale resources in China. Journal of Jilin University (Earth Science Edition), 2006, 36(6), 869875 (in Chinese).

4. Li, S. Y., Ma, Y., Qian, J. L. Global oil shale research, development and utilization today - and an overview of three oil shale symposiums in 2011. SinoGlobal Energy, 2012, 17(2), 8-17 (in Chinese).

5. Bai, Y. L., Tang, H., Yan, K. Geological characteristics and some problems in development for oil shale in Northwest China. Oil Shale, 2011, 28(3), 380-397.

6. Liu, Z. J., Liu, R. Oil shale character and exploitation \& utilization prospect. Earth Science Frontiers, 2005, 12(3), 315-323 (in Chinese).

7. Liu, Z. J., Yang, H. L., Dong, Q. S. et al. Oil Shale in China. Petroleum Industry Press, Beijing, 2009 (in Chinese).

8. Zeng, Y. H., Fu, X. G., Zeng, S. Q. et al. Organic geochemical characteristics of the Bilong Co oil shale (China): implications for paleoenvironment and petroleum prospects. Oil Shale, 2011, 28(3), 398-414.

9. Dyni, J. R. Geology and resources of some world oil-shale deposits. Oil Shale, 2003, 20(3), 193-252.

10. Kang, Z. Q., Zhao, Y. S., Meng, Q. R. et al. Micro-CT experimental research of oil shale thermal cracking laws. Chinese Journal Geophysics, 2009, 52(3), 842 848 (in Chinese). 
11. Kang, Z. Q., Zhao, Y. S., Yang, D. Physical principle and numerical analysis of oil shale development using in situ conversion process technology. Acta Petrolei Sinica, 2008, 29(4), 592-595 (in Chinese).

12. Kang, Z. Q., Yang, D., Zhao, Y. S., Hu, Y. Q. Thermal cracking and corresponding permeability of Fushun oil shale. Oil Shale, 2011, 28(2), 273-283.

Presented by A. Paist

Received May 25, 2012 